\title{
The association of human leukocyte antigen B27 with anterior uveitis in patients from the western region of Saudi Arabia: a retrospective study
}

This article was published in the following Dove Press journal:

Clinical Ophthalmology

29 October 2013

Number of times this article has been viewed

\author{
Ahmed M Bawazeer ${ }^{1,2}$ \\ Heba Ismail Joharjy' \\ 'Uveitis Services, Department \\ of Ophthalmology, King Abdulaziz \\ University, ${ }^{2}$ Magrabi Eye and Ear \\ Hospital, Jeddah, Saudi Arabia
}

Correspondence: Ahmed M Bawazeer Faculty of Medicine, King Abdulaziz University, PO Box 5095, Jeddah 21422, Saudi Arabia

Tel +9665903 30312

Fax +966 I 26408330

Email drbawazeer@yahoo.com
Background: The association of human leukocyte antigen B27 (HLA-B27) with anterior uveitis is well known. The prevalence of HLA-B27 and its relation to anterior uveitis is related to race and geographic location. The association is strongest in Western countries and weakest in Eastern countries. Data regarding this association from Middle Eastern countries are limited. Thus, we undertook the study reported here to evaluate the association of HLA-B27 with anterior uveitis in patients in a tertiary center in the western region of the Saudi Arabia.

Methods: The study involved a retrospective analysis of the records of patients with anterior uveitis, referred to the uveitis clinic in Magrabi Eye and Ear Hospital, Jeddah, Saudi Arabia, from 1999 to 2010. The cost-effectiveness of HLA-B27 testing was analyzed.

Results: Among the 587 cases of uveitis, 335 (57.1\%; mean age 37.56 12.82 years; 203 male and 132 female) cases were of anterior uveitis. All patients with anterior uveitis were investigated for HLA-B27 positivity. Idiopathic anterior uveitis was the most common (80\%), followed by Fuchs heterochromic cyclitis $(7.45 \%)$ and ankylosing spondylitis (3.8\%). Only two patients were HLA-B27 positive. The cost-effectiveness of HLA-B27 testing was found to be 165,000 Saudi riyals (44,594 US dollars) per positive case.

Conclusion: HLA-B27-related uveitis appears to be very rare in our part of the world. Idiopathic uveitis is the most common type of anterior uveitis. The cost-effectiveness of HLA-B27 testing is low for patients with anterior uveitis in the western region of Saudi Arabia.

Keywords: HLA-B27, Saudi population, cost-effectiveness, idiopathic anterior uveitis, Fuchs heterochromic cyclitis, ankylosing spondylitis

\section{Introduction}

"Uveitis" is inflammation of the iris, ciliary body, and choroid. ${ }^{1}$ It can lead to secondary complications - especially if left untreated - such as cataracts, glaucoma, macular scaring, and optic atrophy. ${ }^{2}$ Further, patients become legally blind in $20 \%$ of cases. ${ }^{3}$ Worldwide, anterior uveitis (AU) is the most common type of uveitis with varying incidence (52\%-92\%). ${ }^{4}$ Human leukocyte antigen B27 (HLA-B27)-positive (HLA$\mathrm{B} 27+) \mathrm{AU}(1 \%-23 \%)$ has been reported as less common than HLA-B27-negative (HLA-B27-) AU (31\%-61\%). ${ }^{4}$ The relative frequency of HLA-B27+AU is significantly lower in Japan (6\%), and India (2\%) than in Western countries $(6 \%-32 \%){ }^{4}$ In Saudi Arabia, the frequency ranges between $1.3 \%$ and $2.5 \% .^{5,6}$

The objective of the present study was to evaluate the association between HLAB27 and AU in AU patients who attended the tertiary referral uveitis clinic of Magrabi Eye and Ear Hospital, Jeddah, Saudi Arabia, from 1999 to 2010. 


\section{Materials and methods}

A retrospective analysis of the data of consecutive patients seen in the tertiary referral uveitis clinic of Magrabi Eye and Ear Hospital from 1999 to 2010. The ethical approval for the study was obtained from the Ethical Committee of Magrabi Hospital. Information regarding the age and race of patients was recorded and details of patients' ocular and systemic examinations, investigations, and ocular and systemic disease, if any, were recorded. Patients with post-traumatic (including postoperative) uveitis, Eales disease, and infective endophthalmitis were excluded; all other uveitis cases were included. Our study was in accordance with the guidelines of the Declaration of Helsinki.

The specific ocular uveitis diagnosis or systemic disease association was based on a detailed clinical history, ophthalmological examination, general and physical examination, and laboratory tests. An ocular examination included external examination, slit-lamp biomicroscopy, applanation tonometry, fundus examination with 90/78 D, and dilated and indented indirect ophthalmoscopy. Ultrasonography and fundus fluorescein angiography were carried out when needed.

Anatomical classification of uveitis was done based on the Standardization of Uveitis Nomenclature Working Group classification. ${ }^{7}$ The laboratory tests were complete blood count, erythrocyte sedimentation rate, Treponema pallidum hemagglutination, and serum angiotensin-converting enzyme level. HLA typing for HLA-B27 was done in all patients with AU seen in our uveitis clinic. A diagnosis of presumed ocular herpes was considered when there was clinical evidence of unilateral anterior iritis with sectoral iris atrophy, healed stromal keratitis, and decreased corneal sensation. Tuberculin skin testing was done for all patients. Ocular tuberculosis was presumed in patients with a positive tuberculin test $(>15 \mathrm{~mm})$ and in whom other causes of uveitis could be excluded and a clinical response with multidrug anti-tuberculosis treatment without steroids could be achieved. If the reading was indeterminate $(10-15 \mathrm{~mm})$, a QuantiFERONTM gold test was ordered. A rheumatologist and internist were consulted whenever required for the diagnosis. The diagnosis was considered idiopathic whenever the uveitis could not be attributed to a specific ocular or any underlying systemic disease.

\section{Results}

The present study encountered 587 uveitis patients. Among these, patients with AU constituted 57.1\% (335/587; Table 1). Idiopathic $\mathrm{AU}$ was the commonest ( $80 \%$ ) followed by Fuchs
Table I The etiology of anterior uveitis among the studied cases $(n=335)$

\begin{tabular}{lll}
\hline Parameter & $\mathbf{n}$ & $\%$ \\
\hline Idiopathic & 268 & 80.0 \\
Fuchs heterochromic cyclitis & 25 & 7.4 \\
Ankylosing spondylitis & 13 & 3.8 \\
Herpes simplex virus & 4 & 1.2 \\
Psoriasis & 4 & 1.7 \\
Herpes zoster virus & 3 & 0.8 \\
Juvenile rheumatoid arthritis & 3 & 0.8 \\
Sarcoidosis & 3 & 0.8 \\
Tuberculosis & 3 & 0.8 \\
Human leukocyte antigen B27 & 2 & 0.5 \\
Lens induced & 2 & 0.5 \\
Posner-Schlossman syndrome & 2 & 0.5 \\
Reiter syndrome & $\mathrm{I}$ & 0.3 \\
Rheumatoid arthritis & $\mathrm{I}$ & 0.3 \\
Inflammatory bowel disease & $\mathrm{I}$ & 0.3 \\
\hline
\end{tabular}

heterochromic cyclitis (FHI; 7.4\%) and ankylosing spondylitis (AS; 3.8\%). Of the 587 patients, 203 were male and 132 female. Five of the 13 AS patients were referred by a rheumatologist. These patients were diagnosed by rheumatologists based on old criteria that does not require HLA-B27 for the clinical diagnosis. In these patients, HLA-B27 testing could not be undertaken. HLA-B27 testing was ordered for the remaining 330 patients, including eight AS patients. Only two patients were positive for HLA-B27, neither of who had AS.

A cost-effectiveness study was done to evaluate the costeffectiveness of ordering HLA-B27 testing. Each HLA-B27 test cost 1,000 Saudi riyals (SR) (270 US dollars). The total cost incurred for 330 patients was 330,000 SR (89,189 US dollars). As already noted, only two patients tested positive for HLA-B27.

The cost-effectiveness of ordering HLA-B27 testing for $\mathrm{AU}$ was calculated as the total amount spent on the investigation divided by the number of positive cases $(330,000 / 2)=165,000$ SR per positive case.

\section{Discussion}

AU represents the most common form of uveitis in most regions of the world. ${ }^{4,8}$ It accounts for 50\%-92\% of all uveitis cases in Western countries and $28 \%-50 \%$ of all uveitis cases in Asian countries. ${ }^{4}$ In Saudi Arabia, the incidence varies from $59.5 \%$ to $60.0 \%$ of all uveitis cases. ${ }^{5,9} \mathrm{~A}$ recently published retrospective study reported the incidence of $\mathrm{AU}$ in western Saudi Arabia to be $57.1 \% .^{10}$

In spite of progress in immunological and laboratory investigations, idiopathic anterior uveitis (IAU) still accounts for the majority of AU cases. ${ }^{1,4}$ In the present study, $80 \%$ of the reported cases were diagnosed as IAU. Other 
studies from Saudi Arabia have reported the incidence to be $48.7 \%,{ }^{5} 32.0 \%,{ }^{6}$ and $67.1 \% .{ }^{9}$ Idiopathic uveitis has been found to represent about $38.9 \%-52.9 \%$ of uveitis cases in Middle Eastern countries, ${ }^{11}$ while in Europe it ranges from $32.9 \%$ to $86.7 \%{ }^{12}$ (Table 2 .)

FHI was the second most common cause of AU (7.46\%) in the present study. In their study of patients of Riyadh University Hospital, Al-Mezaine et al reported an FHI incidence of $14.5 \%,{ }^{6}$ while Rodriguez et al reported $7 \%$ in the North East USA, and Yang et al reported 2.5\% in the People's Republic of China. ${ }^{13,14}$

Most cases of AU are frequently related to systemic conditions, of which AS is of special importance. ${ }^{15,16} \mathrm{AS}$ was the third most common cause of AU and constituted 3.8\% of all cases in our study. Islam and Tabbara reported an AS incidence of $2.5 \%$ in their study. ${ }^{5}$

HLA-B2, an allele of class 1 major histocompatibility complex, represents the strongest genetic risk factor for $\mathrm{AU} .8,11,17,18$ Chang and Wakfield ${ }^{4}$ and Chang et $\mathrm{al}^{19}$ have demonstrated that the presence of HLA-B27 antigen increases the risk of AU by 26 times. HLA-B27 exhibits considerable variation in prevalence in different populations. In Caucasians, the presence of HLA-B27 has been found to be $10 \%$ in healthy populations. In Asians (Indians, Japanese), the incidence varies between 1\% and $6 \%{ }^{16,25}$ In the Arab world, the frequency of HLA-B27 in the general population has been reported to be low. Al Attai and $\mathrm{Al}$ Amiri have reported a very low prevalence $(0.5 \%)$ of HLA-B27 in Emirati. ${ }^{20}$ In Kuwait, Alharbi et al found the HLA-B27 prevalence to be $4 \%{ }^{21}$ (Table 3.)

In the present study, HLA-B27 typing was ordered in 330 patients with AU. Only two cases were diagnosed as HLA-B27+. Both were male; one was Egyptian (46 years) and the other was Saudi (28 years). Eight of the 13 patients with AS were negative for HLA-B27, but HLA-B27 testing was not undertaken in the remaining five AS patients who were referred by rheumatologists.

HLA-B27+ AU exhibits a characteristic sex difference, with males being affected 1.5-2.5 times more than females. The first HLA-B27 attack usually occurs between the ages of 20 to 40 years, and it most commonly presents unilaterally. ${ }^{8,18,19}$ In Western countries, HLA-B27 is considered one of the most common causes of AU, with a prevalence ranging from $18 \%$ to $32 \%$, while in Asia, it ranges between $6 \%$ and $13 \%{ }^{4}$

The clinical importance of HLA-B27 typing in uveitis cases is in diagnosis of the associated spondyloarthropathy and subsequent referral to the rheumatologist when the patient is found HLA-B27+.

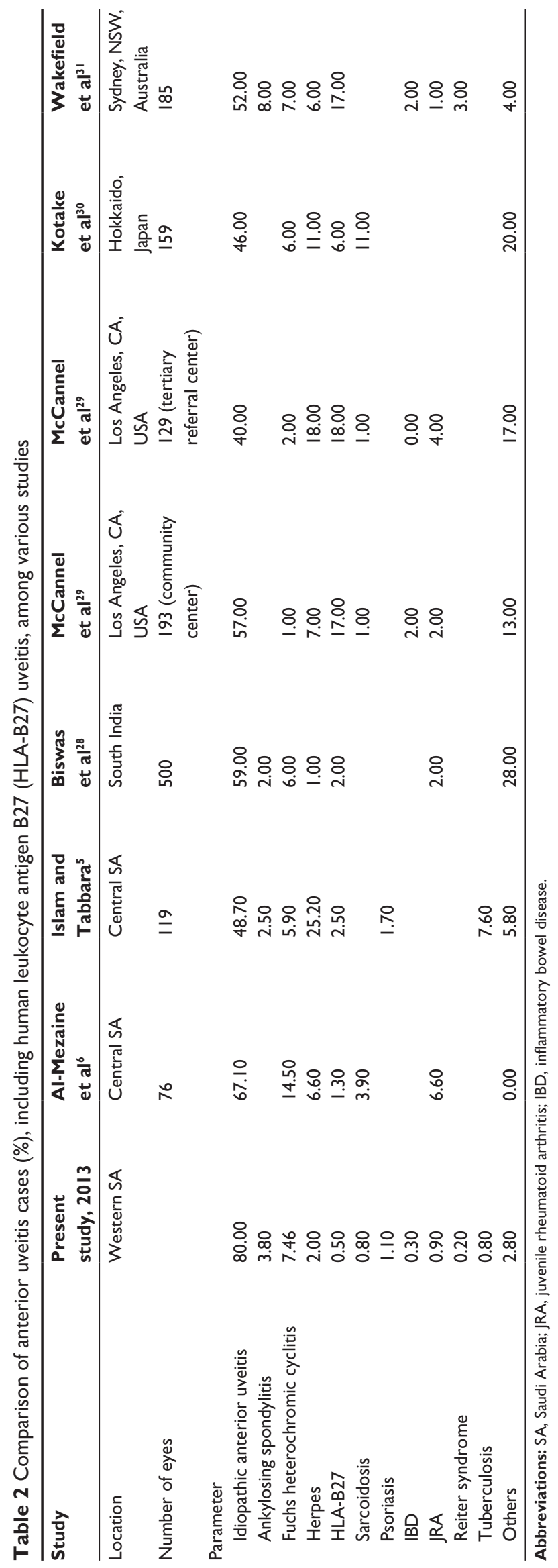


Table 3 Prevalence of human leukocyte antigen B27 (HLA-B27) among different population groups

\begin{tabular}{ll}
\hline Population & HLA-B27 frequency, \% \\
\hline Worldwide $^{8,22}$ & 8.0 \\
Native American ${ }^{16,23,24}$ & \\
$\quad$ Haida Indian of North America & $20.0-50.0$ \\
$\quad$ Eskimo & $25.0-40.0$ \\
UK general & 83,24 \\
Australian Aborigine ${ }^{23,24}$ & 8.0 \\
Asian $^{16,25}$ & 0.0 \\
South Asian & \\
North and central Asian & $5.0-12.0$ \\
$\quad$ Japanese & \\
$\quad$ Korean & $<1.0$ \\
$\quad$ Chinese & 4.0 \\
$\quad$ Tibetan & $2.0-9.0$ \\
Indian & \\
African & \\
North African & 12.0 \\
West African & $2.0-10.0$ \\
South African and Nigerian & \\
Arab & $1.0-5.0$ \\
Emirati & $2.0-10.0$ \\
Saudi Arabian & 0.0 \\
Kuwaiti & \\
Syrian & 0.5 \\
\hline
\end{tabular}

The low numbers of HLA-B27 associated AU $(0.5 \%)$ in the present study and the two studies done in Riyadh by Islam and Tabbara $^{5}$ and Al-Mezaine et $\mathrm{al}^{6}(1.0 \%-2.5 \%)$ could be explained by the fact that the prevalence of HLA-B27 in the general healthy Saudi population is low (2.6\%). Further, unlike the other studies from Saudi Arabia, ${ }^{5,6}$ our patients at Magrabi Eye and Ear Hospital, a private institution, were drawn from the general population (both primary and tertiary centers) from which both simple and complicated cases were referred.

\section{Conclusion}

Among uveitis cases seen in at Magrabi Eye and Ear Hospital, AU was the common form of uveitis. IAU was the most common AU. Only two of 330 AU cases were HLA-B27+. Considering the high cost of HLA-B27 testing (a single test costs around $1000 \mathrm{SR}$ ), ordering HLA-B27 typing for all AU cases may not be cost-effective. Further multicenter studies are needed to evaluate the prevalence of HLA-B27 in both the general population and uveitis cases, which may ultimately decide the cost-effectiveness of ordering HLA-B27 testing routinely in all AU patients in Saudi Arabia.

\section{Acknowledgments}

We thank our colleagues at King Abdulaziz University Hospital, Jeddah, Saudi Arabia, Dr Nizamuddin Shaik Hakim
Mohammad, our vitreo-retinal surgeon, and Dr Sami Bahlas, our rheumatologist, for their help in writing this paper.

\section{Disclosure}

The authors declare no conflicts of interest in relation to this work.

\section{References}

1. Nussenblatt RB, Whitcup SM. Uveitis: Fundamentals and Clinical Practice; Expert Consult. Kindle ed. St Louis, MO, USA: Mosby Elsevier; 2010.

2. Maini R, O'Sullivan J, Reddy A, Watson S, Edelsten C. The risk of complications of uveitis in a district hospital cohort. Br J Ophthalmol. 2004;88(4):512-517.

3. Dandona L, Dandona R, John RK, McCarty CA, Rao GN. Population based assessment of uveitis in an urban population in southern India. Br J Ophthalmol. 2000;84(7):706-709.

4. Chang JH, Wakefield D. Uveitis: a global perspective. Ocul Immunol Inflamm. 2002;10(4):263-279.

5. Islam SM, Tabbara KF. Causes of uveitis at The Eye Center in Saudi Arabia: a retrospective review. Ophthalmic Epidemiol. 2002;9(4): 239-249.

6. Al-Mezaine HS, Kangave D, Abu El-Asrar AM. Patterns of uveitis in patients admitted to a University Hospital in Riyadh, Saudi Arabia. Ocul Immunol Inflamm. 2010;18(6):424-431.

7. Jabs DA, Nussenblatt RB, Rosenbaum JT; Standardization of Uveitis Nomenclature (SUN) Working Group. Standardization of uveitis nomenclature for reporting clinical data. Results of the First International Workshop. Am J Ophthalmol. 2005;140(3):509-516.

8. Chang JH, McCluskey PJ, Wakefield D. Acute anterior uveitis and HLA-B27. Surv Ophthalmol. 2005;50(4):364-388.

9. Hamade IH, Elkum N, Tabbara KF. Causes of uveitis at a referral center in Saudi Arabia. Ocular Immunol Inflamm. 2009;17(1):11-16.

10. Nizamuddin SH, Bawazeer AM. Causes of uveitis in a tertiary center in Western Saudi Arabia. Saudi Med J. 2013;34(4):379-387.

11. Nashtaei EM, Soheilian M, Herbort CP, Yaseri M. Patterns of uveitis in the Middle East and Europe. J Ophthalmic Vis Res. 2011;6(4): 233-240.

12. Chams H, Rostami M, Mohammadi S, Ohno S. Epidemiology and prevalence of uveitis: review of literature. Iranian Journal of Ophthalmology. 2009;21(4):4-16.

13. Rodriguez A, Calonge M, Pedroza-Seres M, et al. Referral patterns of uveitis in a tertiary eye care center. Arch Ophthalmol. 1996;114(5): 593-599.

14. Yang P, Zhang Z, Zhou H, et al. Clinical patterns and characteristics of uveitis in a tertiary center for uveitis in China. Curr Eye Res. 2005; 30(11):943-948.

15. Khan MA, Ball EJ. Genetic aspects of ankylosing spondylitis. Best Pract Res Clin Rheumatol. 2002;16(4):675-690.

16. Niederer R, Danesh-Meyer H. Uveitis screening: HLAB27 antigen and ankylosing spondylitis in a New Zealand population. $N$ Z Med J. 2006;119(1230):U1886.

17. Khan AK. A worldwide overview: the epidemiology of HLA-B27 and associated spondyloarthritides. In: Calin A, Taurog JD, editors. The Spondylarthritides. Oxford: Oxford University Press; 1998:17-26.

18. Loh AR, Acharya NR. Incidence rates and risk factors for ocular complications and vision loss in HLA-B27-associated uveitis. Am J Ophthalmol. 2010;150(4):534-542. e2.

19. Chang JH, McCluskey PJ, Wakefield D. Acute anterior uveitis and HLA-B27: what's new? In: Pleyer U, Forrester JV, editors. Uveitis and Immunological Disorders: Progress III. Berlin and Heidelberg: Springer-Verlag; 2009:9-18.

20. Al Attia HM, Al Amiri N. HLA-B27 in healthy adults in UAE. An extremely low prevalence in Emirian Arabs. Scand J Rheumatol. 1995;24(4):225-227. 
21. Alharbi SA, Mahmoud FF, Al Awadi A, Al Jumma RA, Khodakhast F, Alsulaiman SM. Association of MHC class I with spondyloarthropathies in Kuwait. Eur J Immunogenet. 1996;23(1):67-70.

22. Reveille JD. HLA-B27 and the seronegative spondyloarthropathies. Am J Med Sci. 1998;316(4):239-249.

23. Khan MA. HLA-B27 and its pathogenic role. J Clin Rheumatol. 2008; 14(1):50-52.

24. Sheehan NJ. The ramifications of HLA-B27. J R Soc Med. 2004; 97(1):10-14.

25. Feltkamp TE, Mardjuadi A, Huang F, Chou CT. Spondyloarthropathies in eastern Asia. Curr Opin Rheumatol. 2001;13(4):285-290.

26. Harfouch EI,Al-Cheikh SA. HLA-B27 and its subtypes in Syrian patients with ankylosing spondylitis. Saudi Med J. 2011;32(4):364-368.

27. Braakenburg AM, de Valk HW, de Boer J, Rothova A. Human leukocyte antigen-B27-associated uveitis: long-term follow-up and gender differences. Am J Ophthalmol. 2008;145(3):472-479.
28. Biswas J, Narain S, Das D, Ganesh SK. Pattern of uveitis in a referral uveitis clinic in India. Int Ophthalmol. 1996-1997;20(4):223-228.

29. McCannel CA, Holland GN, Helm CJ, Cornell PJ, Winston JV, Rimmer TG. Causes of uveitis in the general practice of ophthalmology. UCLA Community-Based Uveitis Study Group. Am J Ophthalmol. 1996;121(1):35-46.

30. Kotake S, Furudate N, Sasamoto Y, Yoshikawa K, Goda C, Matsuda H. Characteristics of endogenous uveitis in Hokkaido, Japan. Graefes Arch Clin Exp Ophthalmol. 1997;235(1):5-9.

31. Wakefield D, Dunlop I, McCluskey PJ, Penny R. Uveitis: aetiology and disease associations in an Australian population. Aust NZJ Ophthalmol. 1986;14(3):181-187.
Clinical Ophthalmology

\section{Publish your work in this journal}

Clinical Ophthalmology is an international, peer-reviewed journal covering all subspecialties within ophthalmology. Key topics include: Optometry; Visual science; Pharmacology and drug therapy in eye diseases; Basic Sciences; Primary and Secondary eye care; Patien Safety and Quality of Care Improvements. This journal is indexed on

Submit your manuscript here: http://www.dovepress.com/clinical-ophthalmology-journal

\section{Dovepress}

PubMed Central and CAS, and is the official journal of The Society of Clinical Ophthalmology (SCO). The manuscript management system is completely online and includes a very quick and fair peer-review system, which is all easy to use. Visit http://www.dovepress.com/ testimonials.php to read real quotes from published authors. 